Electronic Supplementary Information

\title{
Solar-Driven Lignin Oxidation via Hydrogen Atom Transfer with a Dye-Sensitized $\mathrm{TiO}_{2}$ Photoanode
}

Shuya Li, ${ }^{\dagger}$ Zhi-Jun Li, ${ }^{\ddagger}$ Hyun Yu, ${ }^{\dagger}$ Marion Ryan Sytu,,${ }^{\dagger}$ Yunxuan Wang,${ }^{\S}$ Debora Beeri,,

Weiwei Zheng, ${ }^{\ddagger}$ Benjamin D. Sherman, ${ }^{*, "}$ Chang Geun Yoo, ${ }^{*, \S}$ Gyu Leem ${ }^{*,+, \perp}$

${ }^{\dagger}$ Department of Chemistry, State University of New York - College of Environmental Science and Forestry, Syracuse, NY 13210, United States

${ }^{\ddagger}$ Department of Chemistry, Syracuse University, Syracuse, New York 13244, United States

${ }^{8}$ Department of Paper and Bioprocess Engineering, State University of New York - College of Environmental Science and Forestry, Syracuse, New York 13210, United States

"Department of Chemistry and Biochemistry, College of Science and Engineering, Texas Christian University, Fort Worth, Texas 76129, United States

${ }^{\perp}$ The Michael M. Szwarc Polymer Research Institute, Syracuse, New York 13210, United States

\section{TABLE OF CONTENTS}

\section{EXPERIMENTAL METHODS}

Materials

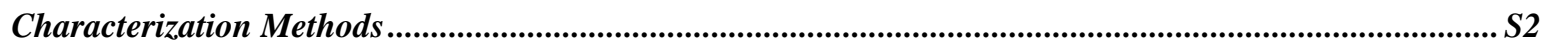

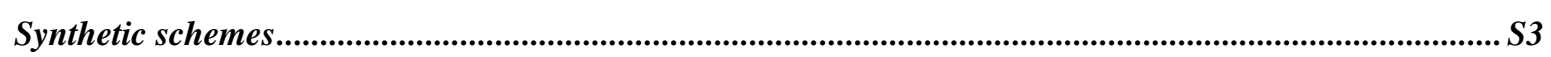

\section{ADDITIONAL DATA}

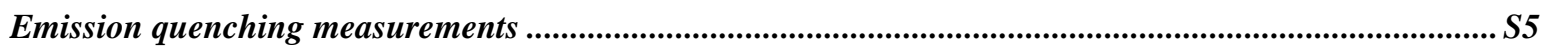

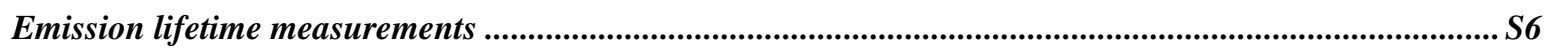

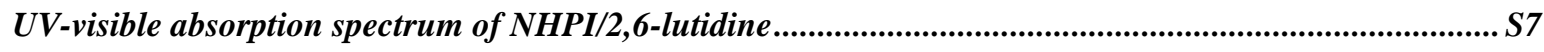

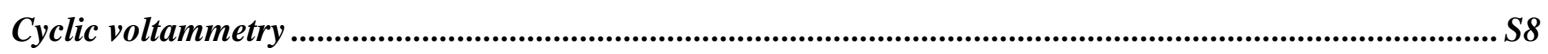

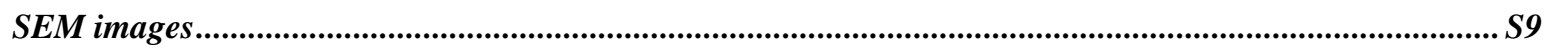

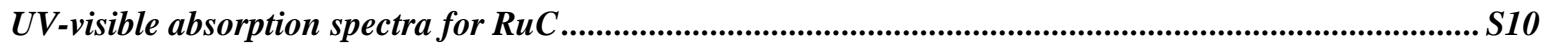

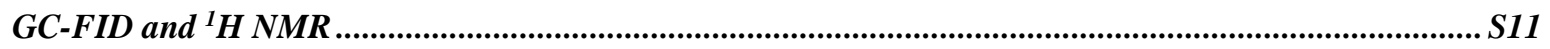

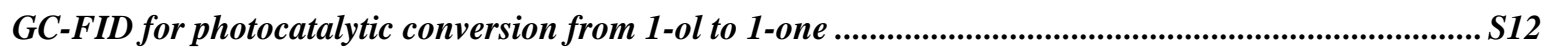

${ }^{1} \mathrm{H}$ and ${ }^{13} \mathrm{C} N \mathrm{NR}$ of 1-one after $20 \mathrm{~h}$ illumination ......................................................................................S13

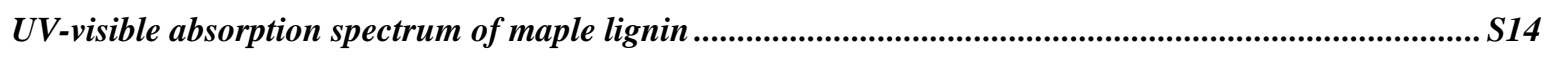

Aliphatic region of 2D HSQC NMR spectra of maple lignin ..................................................................S15

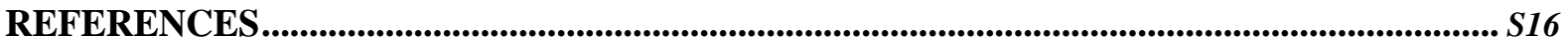




\section{Experimental Methods}

\section{Materials}

(4,4'-Dicarboxy-2,2'-bipyridine)bis(2,2'-bipyridine)ruthenium(II) $\quad$ (RuC), ${ }^{1,2} \quad$ 2-phenoxy-1phenylethanone (1-one), 2-phenoxy-1-phenylethanol (1-ol) were synthesized according to previous reports. ${ }^{3}$ Lignin dimer model compounds, veratrylglycerol- $\beta$-guaiacyl ether and syringylglycerol- $\beta$ guaiacyl ether, were purchased from GreenLignol LLC and used without further purification or modification. Real lignin material was isolated from maple wood. In brief, the biomass was treated using a digester at $160{ }^{\circ} \mathrm{C}$ for $120 \mathrm{~min}$. Lignin was precipitated from the liquid extractant using sulfuric acid by acidifying the liquid to $\mathrm{pH} 2$. The precipitated lignin was recovered by solid/liquid separation and solubilized in acetone. Acetone-soluble lignin fraction was recovered by rotary evaporation and then stored in the refrigerator for the further experiments. Mesoporous nanostructured titanium dioxide films $\left(\mathrm{TiO}_{2}\right)$ on a fluorine doped tin oxide (FTO) electrode were prepared according to a previous report. ${ }^{4,5}$ A LSH-7320 ABA LED Solar Simulator purchased from ORIEL was used.

\section{Characterization Methods}

All synthetized substrates and products were characterized by ${ }^{1} \mathrm{H}$ NMR or/and HSQC NMR and GCFID. NMR spectra were recorded using $\mathrm{CDCl}_{3}$ or deuterated DMSO as solvents on Bruker AVANCE $600 \mathrm{MHz}$ or $800 \mathrm{MHz}$ instruments. The chemical shifts $(\delta)$ are reported in parts per million (ppm) using the residual solvent signals as internal standards (i.e. 7.26 for $\mathrm{CDCl}_{3}$ ). GC-FID data were obtained by a Thermo Focus GC equipped with a Flame Ionization Detector. UV-vis absorption measurements were carried out on Thermo Evolution 220 UV-visible spectrophotometer. Cyclic voltammetry (CV) measurements and chronoamperometry measurements were performed on a Pine WaveNow potentiostat. Emission spectra and fluorescence lifetime measurements were obtained by using an Edinburgh FLS 980 steady state and time-resolved emission spectrometer. The lifetimes detected from time-resolved photoluminescence measurements were calculated using following equation:

$$
<\tau>=\frac{\sum_{i=1}^{2} \alpha_{i} \tau_{i}^{2}}{\sum_{i=1}^{2} \alpha_{i} \tau_{i}}
$$

Where $\langle\tau\rangle$ is experimentally detected by PL decay; $\alpha_{\mathrm{i}}$ is the fractional amplitude of component $\mathrm{i}$; $\tau_{i}$ is the lifetime of component $i$; and $i$ is the number of exponentials.

HSQC NMR. ${ }^{1} \mathrm{H}$ and two-dimensional (2D) ${ }^{1} \mathrm{H}-{ }^{13} \mathrm{C}$ heteronuclear single quantum coherence (HSQC) nuclear magnetic resonance (NMR) analyses were conducted with lignin model compounds and isolated lignin (cellulolytic enzyme lignin) before and after photocatalytic oxidation in a DSPEC. About $5 \mathrm{mg}$ of lignin samples were dissolved in $0.5 \mathrm{~mL}$ of NMR solvents (model compounds in $\mathrm{CDCl}_{3}$ or isolated lignin in DMSO- $d_{6}$ ). The analysis was conducted using Bruker AVANCE III HD $800 \mathrm{MHz}$ equipped with TCI Cryo probe. The solvent peak served as the internal reference, and the acquisition parameters were as follows: 12 ppm spectral width in $\mathrm{F} 2\left({ }^{1} \mathrm{H}\right)$ dimension with 1024 data points and 160 ppm spectral width in $\mathrm{F} 1\left({ }^{13} \mathrm{C}\right)$ dimension with 512 data points, a 1.2 -s pulse delay, and 32 scans. The ${ }^{1} \mathrm{H}-{ }^{13} \mathrm{C}$ HSQC experiment was conducted with a standard Bruker HSQC pulse sequence (hsqcetgpsis2), and the volume integration of contours in HSQC spectra was performed using Bruker TopSpin 4.0.6 (Mac version) software. The assignments of lignin samples were made according to the literature. ${ }^{6}$

Fabrication of dye-sensitized $\mathbf{~ F T O} \mid \mathrm{TiO}_{2}$ electrodes. $\mathrm{TiO}_{2}$ nanoparticles and dye-sensitized $\mathrm{FTO} \mid \mathrm{TiO}_{2}$ electrodes were prepared and fabricated using a modified procedure previously reported in the literatures. ${ }^{5,7} 40 \mathrm{~mL}$ deionized water and $12.4 \mathrm{~mL}$ of glacial acetic acid were mixed together and stirred at $0{ }^{\circ} \mathrm{C} .1 .5 \mathrm{~mL}$ isopropanol and $6 \mathrm{~mL}$ titanium(IV) isopropoxide (TIP) were added into a septum sealed vial under nitrogen gas. Then the TIP/isopropanol mixture was added dropwise into the $\mathrm{H}_{2} \mathrm{O} /$ acetic acid solution to form a thick, opaque, and yellow mixture. This mixture was then heated to $120{ }^{\circ} \mathrm{C}$ under reflux for $4 \mathrm{~h}$. After that, the mixture turned a white, opaque, and milk-like consistency. A Parr $125 \mathrm{~mL}$ acid digestion vessel with Teflon liner was used to load $60 \mathrm{~mL}$ of the white solution, and this assembled 
vessel heated at $200{ }^{\circ} \mathrm{C}$ for $12 \mathrm{~h}$ in a box furnace. $30 \mathrm{~mL}$ of $\mathrm{TiO}_{2} \mathrm{NPs}$ solution was sonicated to form a homogeneous mixture. The volume of the solution was then reduced to $\sim 5-8 \mathrm{~mL}$ using a rotary evaporator. Polyethylene glycol (PEG, $\left.\mathrm{M}_{\mathrm{w}} \sim 20000\right)$ and polyethylene oxide (PEO, $\mathrm{M}_{\mathrm{w}} \sim 100 \mathrm{k}$ ) were added to the $\mathrm{TiO}_{2} \mathrm{NPs}$ solution to give $2.5 \mathrm{wt} \%$ of both polymers to the solution. The mixture was then stirred for $48 \mathrm{hr}$ before fabricating electrodes.

Mesoporous FTO|TiO ${ }_{2}$ films were prepared by a doctor blade method. The films were then sintered by heating them at a rate of $5{ }^{\circ} \mathrm{C} / \mathrm{min}$ to a final temperature of $450{ }^{\circ} \mathrm{C}$ and keeping this temperature for 1 h. The films were slowly cooled down to room temperature. The $\mathrm{FTO}^{\mathrm{T}} \mathrm{TiO}_{2}$ film was immersed into a solution of $1 \mathrm{mg} / \mathrm{mL} \mathbf{R u C}$ in acetonitrile (ACN) of for $24 \mathrm{~h}^{4}$

Photocurrent and Photocatalytic oxidation measurements: Photocurrent and photocatalytic measurements were carried out with a Pine WaveNow potentiostat for the photoanodes under an applied bias of $0.75 \mathrm{~V}$ versus $\mathrm{SCE}$ in $0.1 \mathrm{mM} \mathrm{TBAPF} 6$ acetone solution. Light irradiation was provided by an AM1.5 (200 $\mathrm{mW} / \mathrm{cm}^{2}$ visible light) LED solar simulator. The temperature in the DSPEC photoanode was maintained at ambient temperature by cooling with forced air by using an electric fan.

\section{Synthetic schemes}

\section{1. (4,4'-Dicarboxy-2,2'-bipyridine)bis(2,2'-bipyridine)ruthenium(II) dichloride (RuC-Cl) ${ }^{1}$}

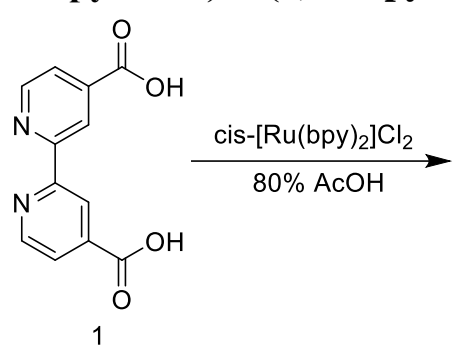

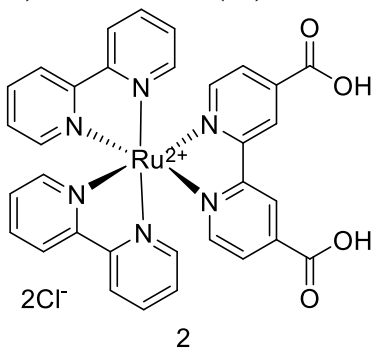

A mixture of 2,2'-bipyridine-4,4'-dicarboxylic acid $(2.44 \mathrm{~g}, 10 \mathrm{mmol}, 1)$ and cis-bis(2,2'bipyridine)ruthenium(II) dichloride dihydrate $(5.2 \mathrm{~g}, 10 \mathrm{mmol})$ in $80 \%$ acetic acid $(100 \mathrm{~mL})$ was stirred for $5 \mathrm{~h}$ under reflux, and the solvent was removed under vacuum. The resulting dark red solid was dissolved in a minimum amount of ethanol $(50 \mathrm{~mL})$ in the presence of concentrated hydrochloric acid $(0.5 \mathrm{~mL})$, the solution was filtered through a Celite pad, the filtrate was concentrated to $40 \mathrm{~mL}$, and the diacid was precipitated by gradual addition of diethyl ether $(\sim 100 \mathrm{~mL})$. After stirring for $1 \mathrm{~h}$ at room temperature, the dark red product was separated, washed with diethyl ether and dried at $60{ }^{\circ} \mathrm{C}$ : yield $7.2 \mathrm{~g}(94 \%) ;{ }^{1} \mathrm{H}$ NMR (DMSO-d 6 ) $\delta 9.24(\mathrm{~s}, 2 \mathrm{H}), 8.86(\mathrm{~m}, 4 \mathrm{H}), 8.18(\mathrm{~m}, 4 \mathrm{H}), 7.91(\mathrm{~d}, 2 \mathrm{H}), 7.86(\mathrm{dd}$, 2H), 7.76-7.71 (m, 4H), 7.57-7.48 (m, 4H).

2. RuC. ${ }^{2}$ The RuC-Cl with $\mathrm{Cl}$ counter anions underwent anion metathesis using a saturated potassium hexafluorophosphate solution in methanol to obtain the $\mathrm{PF}_{6}{ }^{-}$salt of $\mathbf{R u C}$ product. 


\section{2-Phenoxy-1-phenylethanone (1-one) ${ }^{3}$}<smiles>O=C(CBr)c1ccccc1</smiles>

3

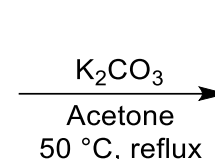

$50{ }^{\circ} \mathrm{C}$, reflux<smiles>O=C(COc1ccccc1)c1ccccc1</smiles>

2-Bromoacetophenone (11.94 g, $60 \mathrm{mmol}$ ), phenol (7.0582 g, $75 \mathrm{mmol})$, and $\mathrm{K}_{2} \mathrm{CO}_{3}(12.3 \mathrm{~g}, 89 \mathrm{mmol})$ were dissolved in $250 \mathrm{~mL}$ acetone and heated at $50{ }^{\circ} \mathrm{C}$ under reflux and stirring. After $12 \mathrm{~h}$, the mixture was filtered and concentrated in vacuo. The vacuo residue was poured into distilled water in which the volume ratio of water and residue is larger than 10:1. Then final product precipitated after $10 \mathrm{~h}$ and 1one was crystallized from $250 \mathrm{~mL}$ of cold ethanol ( $80 \%$ yield). ${ }^{1} \mathrm{H}$ NMR (600 MHz, Chloroform-d) $\delta$ : 6.92 - $8.02(\mathrm{~m}, 10 \mathrm{H}), 5.27$ (s, 2H). ${ }^{13} \mathrm{C}$ NMR (600 MHz, Chloroform-d) $\delta: 194.93,158.42,135.04$, $134.16,129.92,129.16,128.52,122.02,115.21,71.24$.

\section{2-Phenoxy-1-phenylethanol (1-ol) ${ }^{3}$}

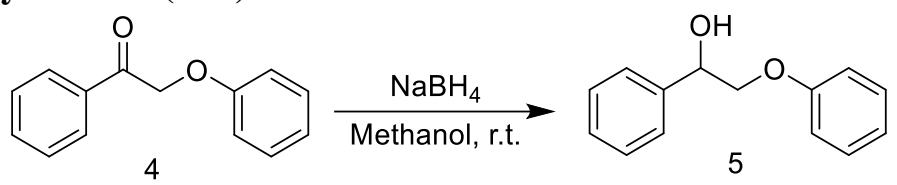

Sodium borohydride ( $0.3534 \mathrm{~g}, 10.4 \mathrm{mmol})$ was added gradually into the mixture of 1-one $(1.1089 \mathrm{~g}$, $5.2 \mathrm{mmol}$ ) and $35 \mathrm{~mL}$ of methanol, generating a gentle gas evolution. Then the mixture was stirred at room temperature for $5 \mathrm{~h}$, after which the reaction mixture was quenched with $30 \mathrm{~mL}$ of saturated aqueous $\mathrm{NH}_{4} \mathrm{Cl}$ and the organic phase was extracted with diethyl ether. The ether solution was dried with $50 \mathrm{~mL}$ saturated brine solution, filtered, and evaporated in vacuo yielding a white solid of 1-ol. ${ }^{1} \mathrm{H}$ NMR (600 MHz, Chloroform-d) $\delta: 7.51$ - 7.26 (m, 7H), 7.04-6.93 (m, 3H), 5.13 (dd, 1H), 4.12 (dd, 1H), 4.02 (dd, 1H). ${ }^{13} \mathrm{C}$ NMR (600 MHz, Chloroform-d) $\delta: 158.77,140.06,129.90,128.90,126.63,121.67$, $115.04,73.69,72.95$. 


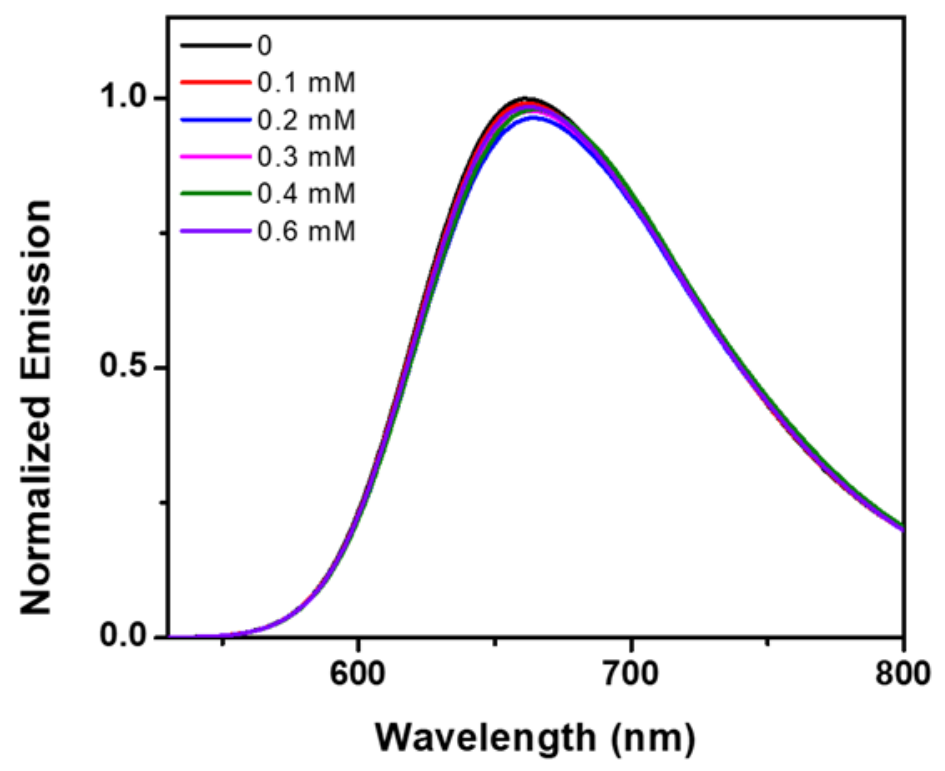

Fig. S1. Emission quenching of RuC by NHPI $(0-0.6 \mathrm{mM})$ in degassed acetonitrile solution acquired with excitation at $\lambda_{\mathrm{ex}}=460 \mathrm{~nm}$. 

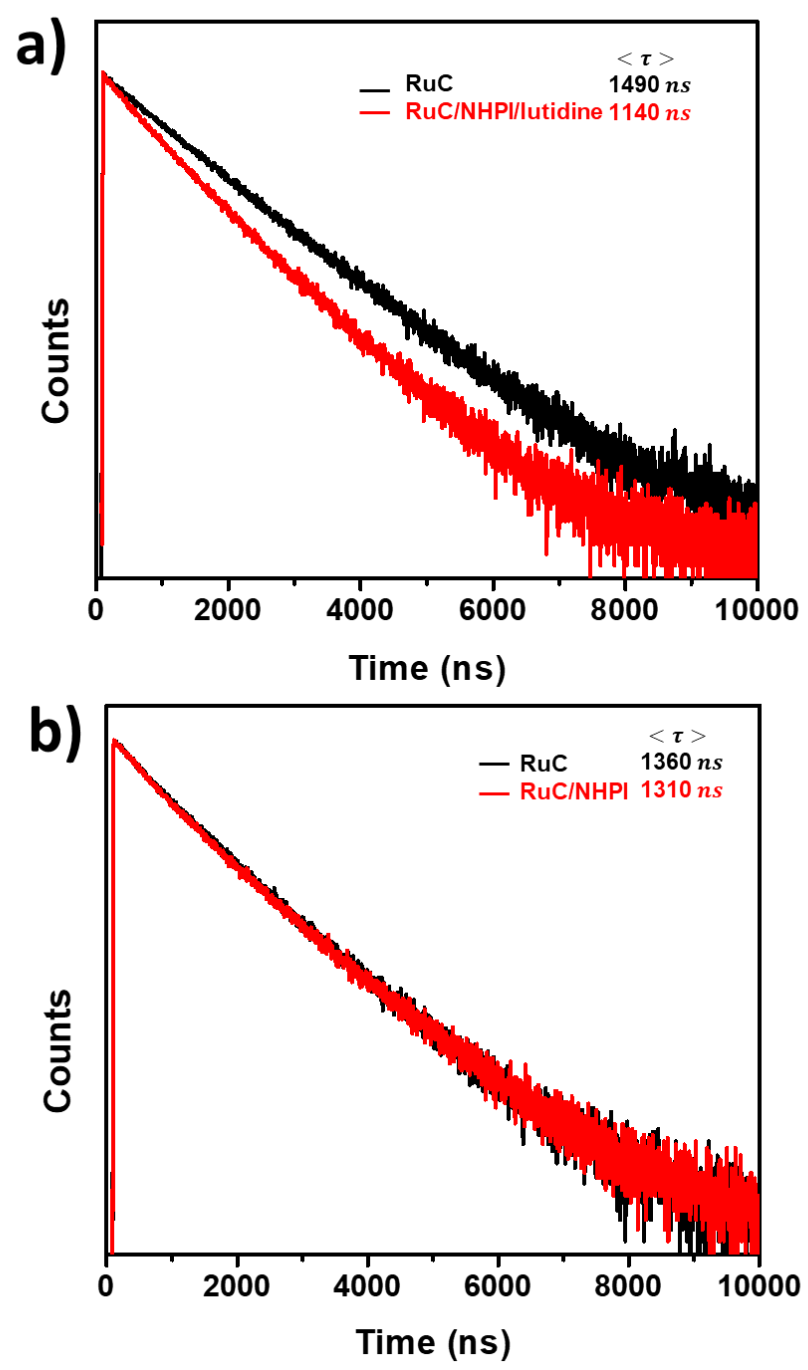

Figure S2. Emission lifetime measurements of RuC with (red line) and without (black line) 1:1 (0.8 $\mathrm{mM}$ ) (a) NHPI/lutidine and (b) NHPI only monitored at $650 \mathrm{~nm}$ following $410 \mathrm{~nm}$ excitation. The decays are fit to a bi-exponential function. 


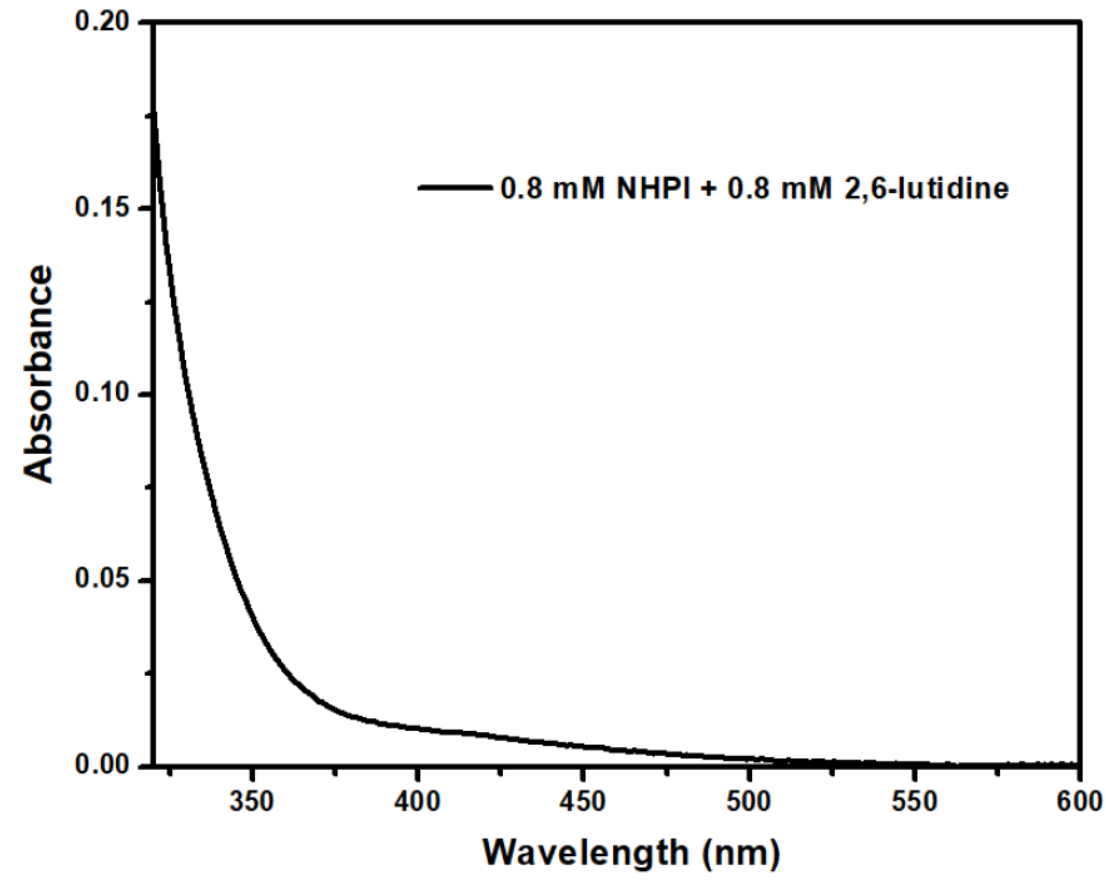

Figure S3. UV-visible absorption spectrum of $0.8 \mathrm{mM}$ NHPI and $0.8 \mathrm{mM}$ 2,6-lutidine in acetonitrile. 


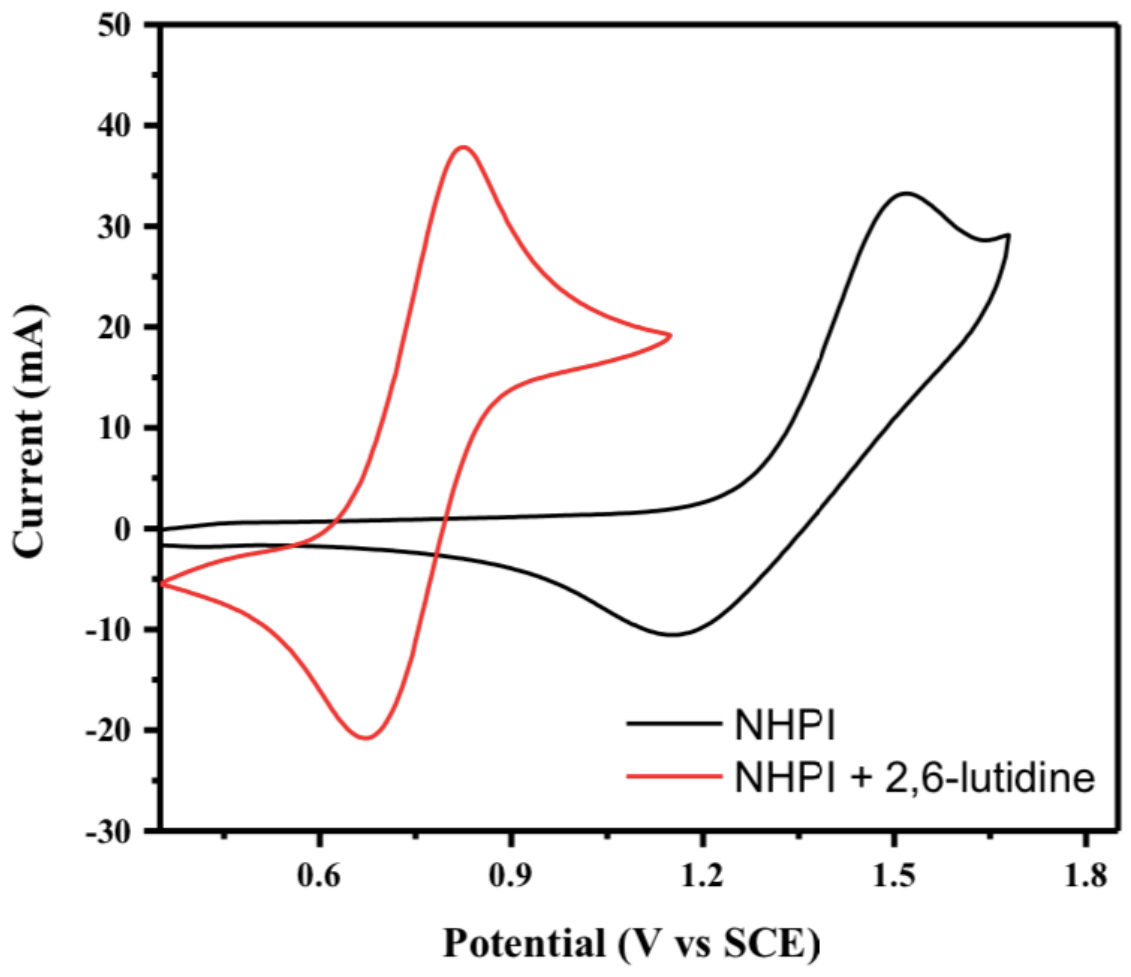

Figure S4. Cyclic voltammetry of NHPI (black, 5mM) and NHPI/2,6-lutidine (red, $5 \mathrm{mM}$ each) in acetonitrile. Voltammograms acquired using a glassy carbon working electrode, Pt counter electrode, and $\mathrm{Ag}^{+} / \mathrm{Ag}$ quasi-reference, in $\mathrm{ACN}$ with $0.1 \mathrm{M} \mathrm{TBAPF}_{6}$ supporting electrolyte. $\mathrm{Fc}^{+} / \mathrm{Fc}=0.45 \mathrm{~V}$ vs SCE was used to convert the potential scale to SCE. 

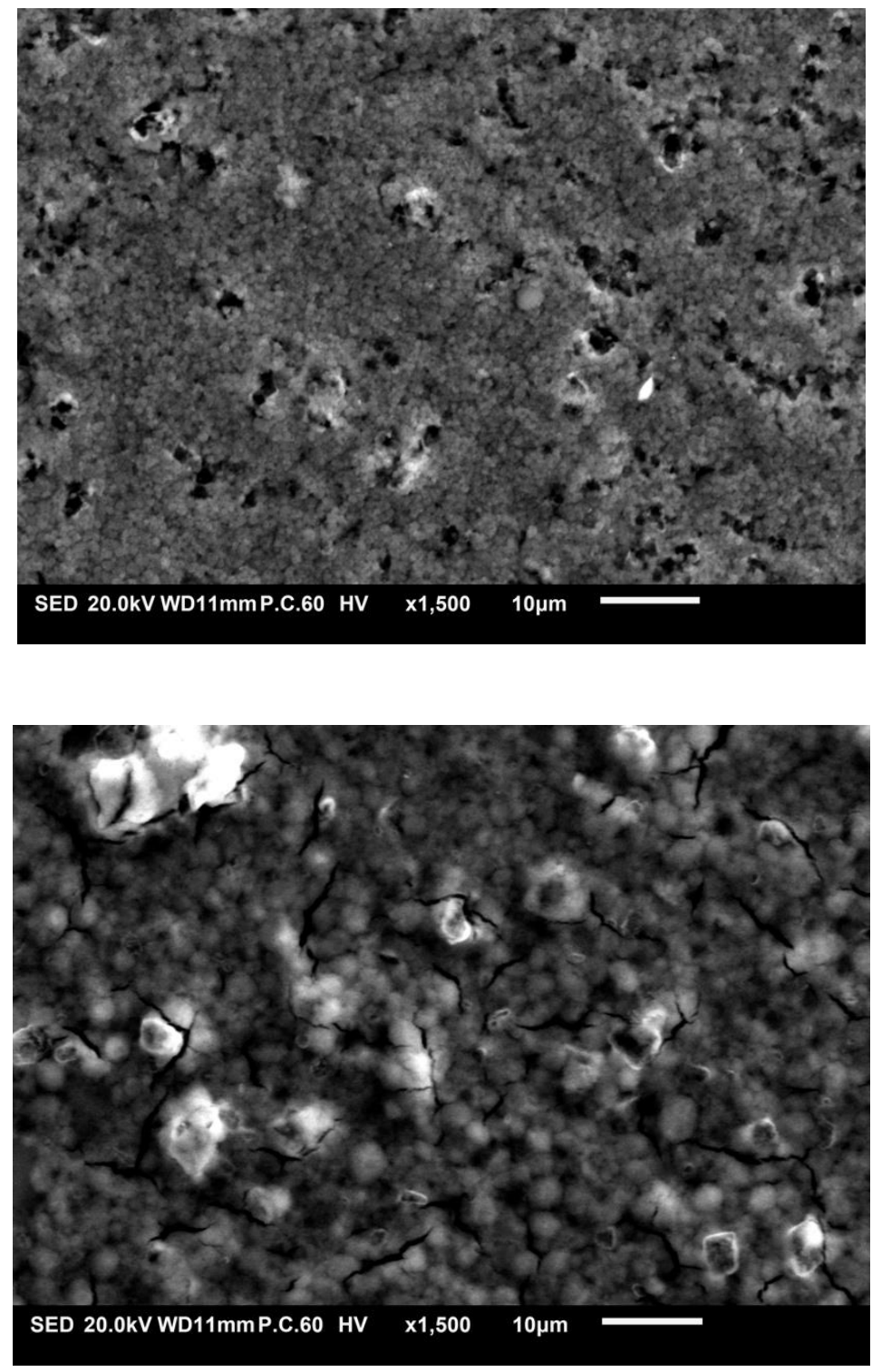

Figure S5. SEM images of unmodified films of $\mathrm{FTO}_{\mid \mathrm{TiO}_{2}}$ (top), and $\mathrm{FTO} \mid \mathrm{TiO}_{2}-\mathbf{R u C}$ films (bottom). 


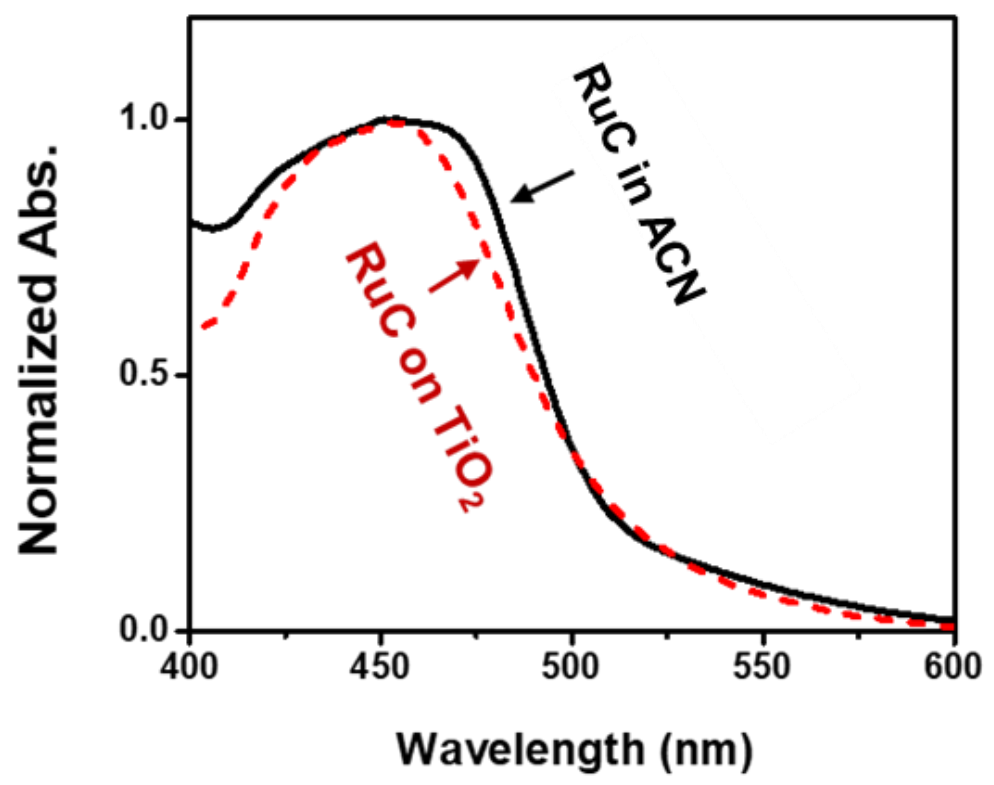

Figure S6. UV-visible absorption spectra for RuC in solution (solid black line) and for $\mathrm{FTO}^{\mathrm{T}} \mathrm{TiO}_{2-}$ RuC (dotted red line). 
Before Illumination
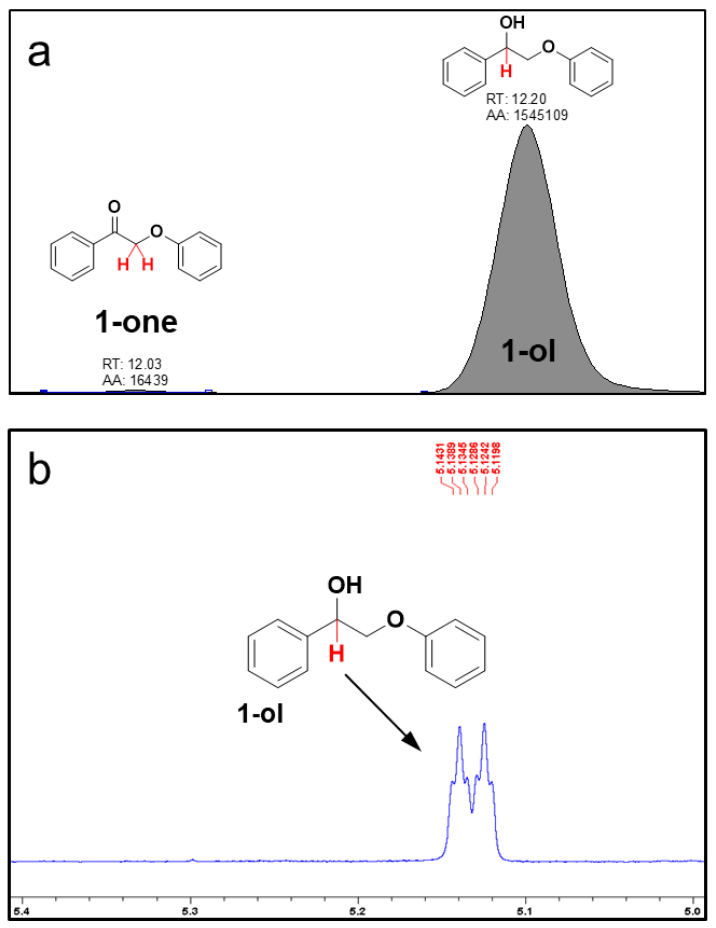

After illumination
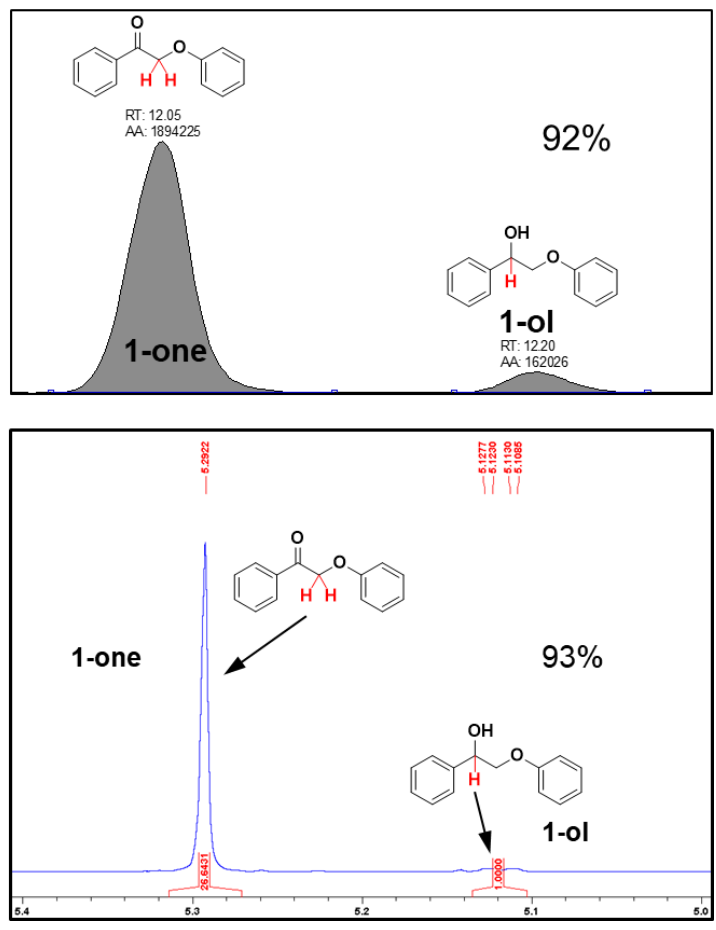

Figure S7. Photocatalytic conversion of 1-ol to the oxidized product, 1-one before (left panels) and after illumination (right panels). (a) Retention times of 1-ol and 1-one in GC-FID measurements. (b) chemical shift in ${ }^{1} \mathrm{H}$ NMR measurement, characteristic peaks for 1-ol and 1-one before and after $20 \mathrm{~h}$ illumination. 

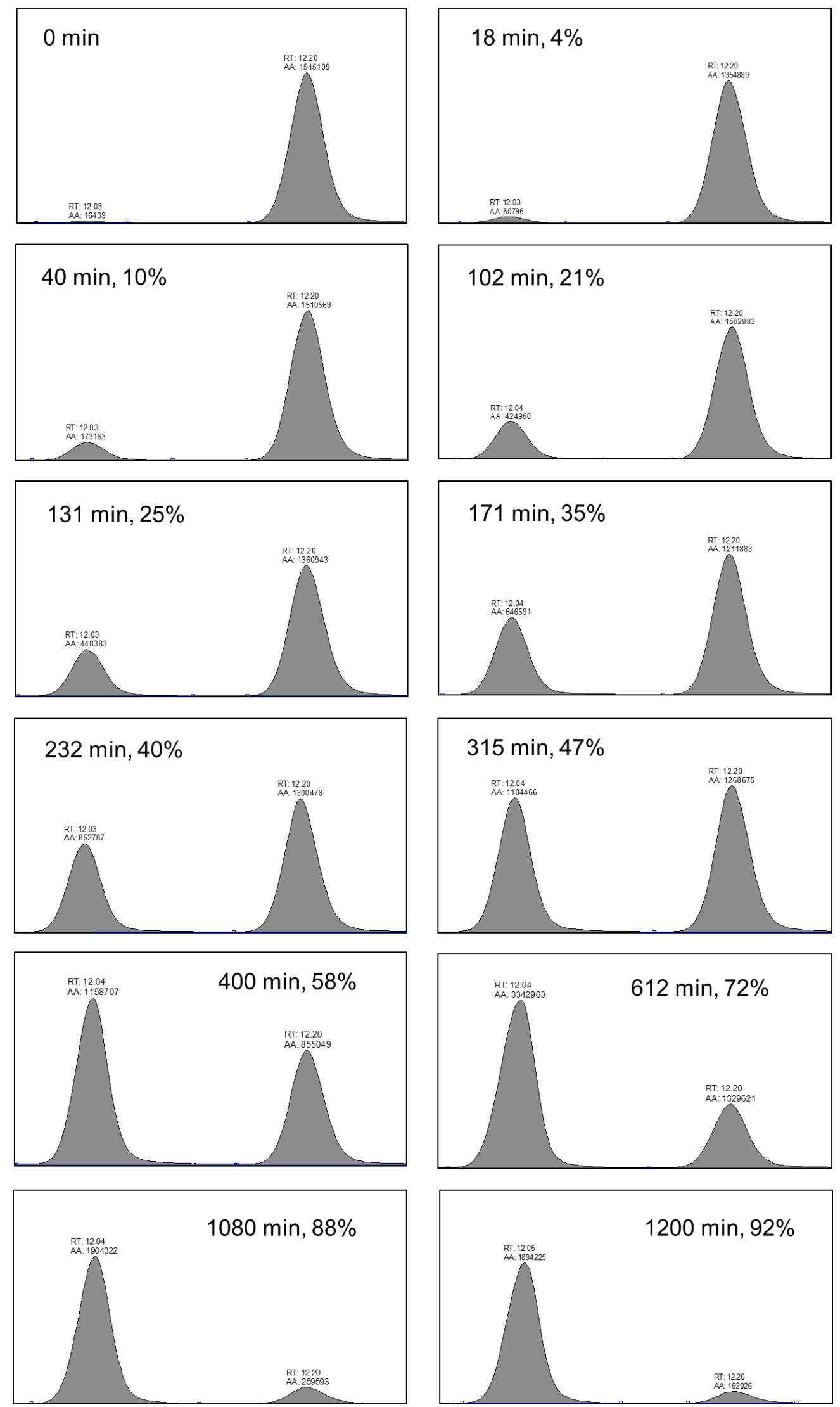

Fig. S8. GC-FID for photocatalytic conversion from 1-ol to 1-one over a 20 hour experiment. 
${ }^{1} \mathrm{H}$ NMR<smiles>OC(Cc1ccccc1)c1ccccc1</smiles><smiles>O=C(COc1ccccc1)c1ccccc1</smiles>

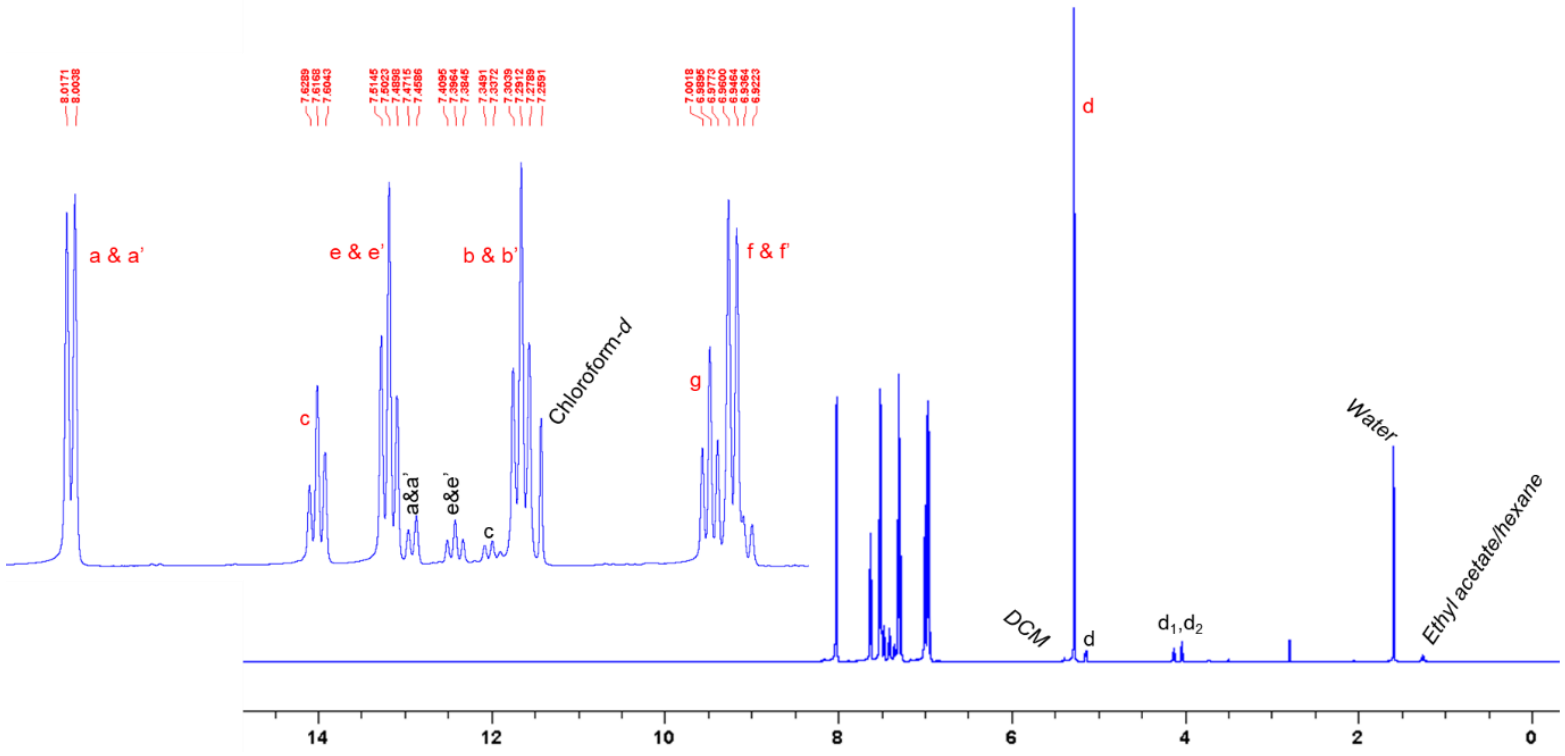

${ }^{13} \mathrm{C}$ NMR

|

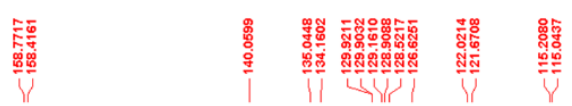<smiles>O=C(COc1ccccc1)c1ccccc1</smiles>

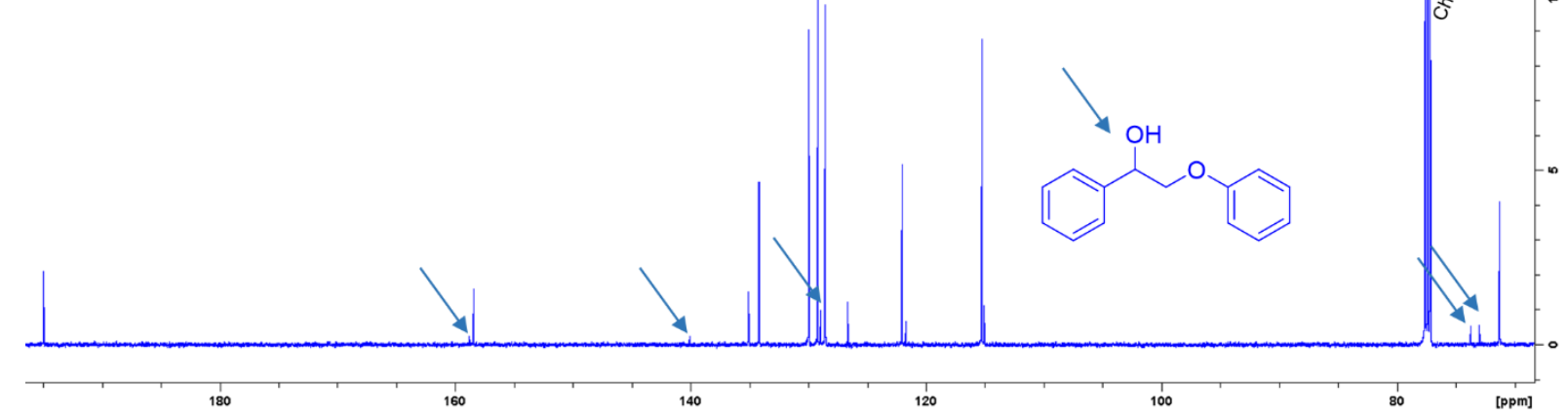

Figure S9. ${ }^{1} \mathrm{H}$ and ${ }^{13} \mathrm{C}$ NMR of 1-one after $20 \mathrm{~h}$ illumination. 


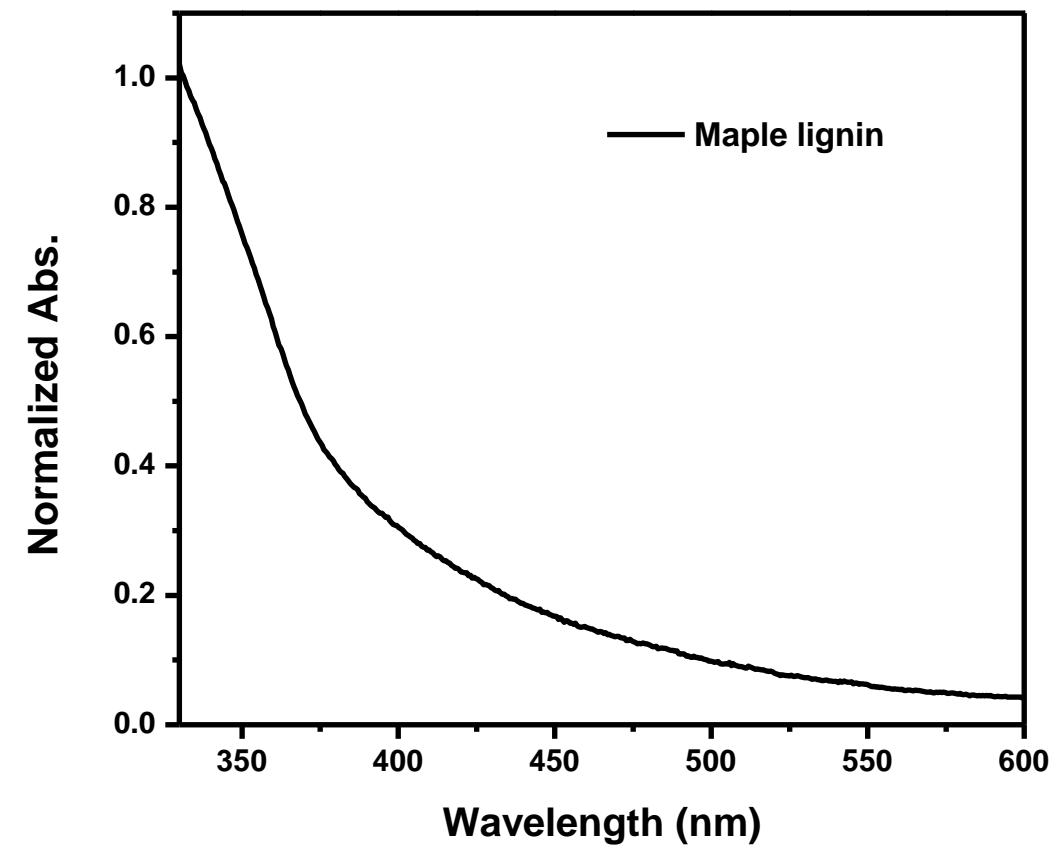

Fig. S10. UV-visible absorption spectrum of maple lignin in acetone. 

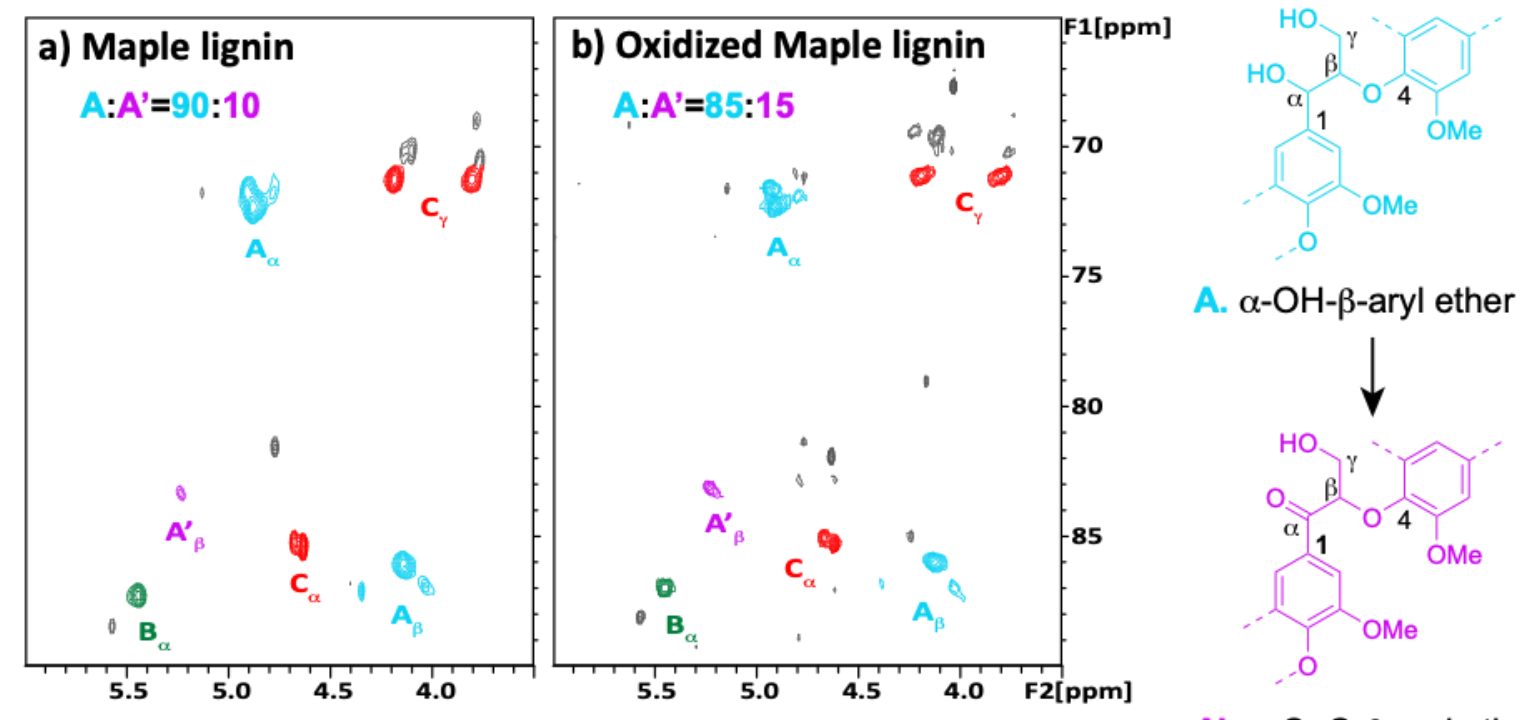

$A^{\prime} \cdot \alpha-C=0-\beta$-aryl ether

Fig. S11. Aliphatic region of 2D HSQC NMR spectra of an isolated Maple lignin (DMSO- $d_{6}$ ) (a) before and (b) after photocatalytic oxidation in the DSPEC photoanode. The relative content of $\alpha-\mathrm{C}=\mathrm{O}-\beta$-aryl ether was calculated by the relative area of $\alpha$-C $=\mathrm{O}-\beta$-aryl ether linkages $\left(\mathrm{A}^{\prime}{ }_{\beta}\right)$ over total $\beta$-aryl ether linkages $\left(\mathrm{A}_{\beta}{ }_{\beta}\right.$ $\left.+\mathrm{A}_{\beta}\right)$. 


\section{REFERENCES}

(1) Beer, P. D.; Szemes, F.; Balzani, V.; Salà, C. M.; Drew, M. G. B.; Dent, S. W.; Maestri, M. Anion Selective Recognition and Sensing by Novel Macrocyclic Transition Metal Receptor Systems. 1H NMR, Electrochemical, and Photophysical Investigations. J. Am. Chem. Soc. 1997, 119, 11864-11875.

(2) Leem, G.; Keinan, S.; Jiang, J.; Chen, Z.; Pho, T.; Morseth, Z. A.; Hu, Z.; Puodziukynaite, E.; Fang, Z.; Papanikolas, J. M.; Reynolds, J. R.; Schanze, K. S. Ru(bpy) ${ }_{3}{ }^{2+}$ Derivatized Polystyrenes Constructed by Nitroxide-Mediated Radical Polymerization. Relationship Between Polymer Chain Length, Structure and Photophysical Properties. Polym. Chem.2015, 6, 8184-8193.

(3) Sun, K.; Chen, S.; Zhang, J.; Lu, G.-P.; Cai, C. Cobalt Nanoparticles Embedded in N-Doped Porous Carbon Derived from Bimetallic Zeolitic Imidazolate Frameworks for One-Pot Selective Oxidative Depolymerization of Lignin. ChemCatChem 2019, 11, 1264-1271.

(4) Kang, M. G.; Park, N.-G.; Park, Y. J.; Ryu, K. S.; Chang, S. H. Manufacturing Method for Transparent Electric Windows Using Dye-Sensitized $\mathrm{TiO}_{2}$ Solar Cells. Sol. Energy Mater. Sol. Cells 2003, 75, 475-479.

(5) Leem, G.; Morseth, Z. A.; Puodziukynaite, E.; Jiang, J.; Fang, Z.; Gilligan, A. T.; Reynolds, J. R.; Papanikolas, J. M.; Schanze, K. S. Light Harvesting and Charge Separation in a $\pi$-Conjugated Antenna Polymer Bound to $\mathrm{TiO}_{2}$. J. Phys. Chem. C 2014, 118, 28535-28541.

(6) Rahimi, A.; Azarpira, A.; Kim, H.; Ralph, J.; Stahl, S. S. Chemoselective Metal-Free Aerobic Alcohol Oxidation in Lignin. J. Am. Chem. Soc. 2013, 135, 6415-6418.

(7) Leem, G.; Morseth, Z. A.; Wee, K.-R.; Jiang, J.; Brennaman, M. K.; Papanikolas, J. M.; Schanze, K. S. Polymer-Based Ruthenium(II) Polypyridyl Chromophores on $\mathrm{TiO}_{2}$ for Solar Energy Conversion.

Chem. Asian J. 2016, 11, 1257-1267. 